\title{
Optimization Design Framework for Integrally Twisted Helicopter Blades
}

\author{
Carlos E. S. Cesnik* Jiwon Mok ${ }^{\dagger}$ Anish S. Parikh \\ Department of Aerospace Engineering \\ University of Michigan, Ann Arbor, Michigan, USA \\ and \\ SangJoon Shin ${ }^{\S}$ \\ School of Mechanical and Aerospace Engineering \\ Seoul National University, Seoul, Korea
}

\begin{abstract}
This paper presents the initial development of an optimization framework for designing active twist helicopter rotor blade cross sections with embedded anisotropic piezocomposite actuators. Optimum design of active twist blades is a complex task, since it involves a rich design space with tightly coupled design variables, e.g., the simple orientation of the actuators affects the blade natural frequencies. Therefore, it becomes advantageous to apply the principle of mathematical optimization to the design task. In the proposed framework, the blade cross-sectional internal layout is designed to maximize the static twist actuation while satisfying a series of blade requirements. These requirements are associated with locations of the center of gravity and elastic axis, blade mass per unit span, fundamental rotating blade frequencies, and the blade strength based on local threedimensional stress and strain fields under worst loading conditions. An active composite cross-sectional analysis and a geometrically exact one-dimensional beam analysis, along with other related analysis routines, are combined with a gradient-based optimizer within MATLAB. The developed optimization framework is exemplified by using the NASA/Army/MIT Active Twist Rotor blade and its baseline design.
\end{abstract}

\section{INTRODUCTION}

The high levels of vibration in helicopters is a very serious problem for the vehicle, its operation, and maintainance. It is associated with the highly unsteady aerodynamic environment that surrounds the rotor system, particularly during forward flight. Higher harmonic control and individual blade control have been suggested as ways to reduce helicopter vibrations $[1,2]$. These methods directly modify the excitation forces, principally aerodynamic forces acting on the rotor blades, to reduce or eliminate vibration. Higher harmonic control (HHC) is accomplished by manipulating a conventional swashplate to enable blade pitch control at an integral multiple of the rotor rotating frequency, i.e., $(k N \pm 1) /$ rev. Individual blade control (IBC) uses a feathering actuator in each blade to control the blade pitch at arbitrary frequencies. These methodologies satisfactory reduce, in general, the vibratory loads on the fixed or rotating systems $[1,3]$. However, there have been several problems associated with their implementation that prevent further deployment in production helicopters. These include excessive power requirement, limitations on actuator excitation frequency, and, in particular for IBC, the extreme mechanical complexity required for hydraulic sliprings.

\footnotetext{
*Associate Professor of Aerospace Engineering.

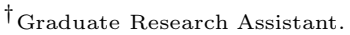

$\ddagger_{\text {Graduate Research Assistant. }}$

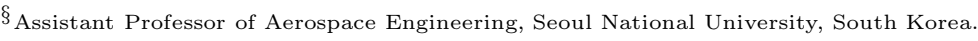

Copyright(C) 2004 by Carlos E. S. Cesnik, Jiwon Mok, Anish S. Parikh, and SangJoon Shin. Published by the American Institute of Aeronautics and Astronautics, Inc., with permission.
}

American Institute of Aeronautics and Astronautics 
A variety of actuation mechanisms based on active materials have more recently been suggested to overcome those problems $[4,5,6,7]$. By replacing the traditional hydraulic systems with active material-based actuators, potential advantages can be obtained in terms of mechanical complexity, weight, power consumption, and bandwidth. Active Twist Rotor (ATR) blades like the one developed under the NASA/Army/MIT ATR program present themselves as a potential solution for helicopter rotor individual blade control. By individually controlling each blade twist, local changes to the vibratory loads will result. If this is done at the appropriate phase, it will result in a reduction of the vibrations transmitted to the fuselage through the rotor hub.

In the NASA/Army/MIT Active Twist Rotor program, analysis and design methodologies were developed for active blades with embedded piezocomposite actuators [8]. Using these methodologies, an ATR prototype blade was designed and fabricated for bench/hover tests [9, 10]. After minor design modifications, a set of active blades were manufactured and wind-tunnel tested in forward flight [11, 12]. During the open-loop forward flight test, significant authority on both fixed- and rotating-system loads was observed from the twist actuation [11, 12]. Finally, a closed-loop controller was designed to reduce the ATR hub vertical shear vibratory loads and implemented successfully in the Langley wind tunnel experimental setup [13].

The blade design for that program was accomplished through exploration of several design candidates based on an existing passive blade [14]. Through different candidates, few design variables were varied, such as the number of active layers, length of the active region in the chordwise direction, and the location of the active layers inserted in the cross section. Among those candidates, the one that exhibited the largest static twist actuation performance was selected as the final design candidate [14]. Simultaneously, the other blade design parameters were kept at an appropriate range to give similar characteristics as the ones from the baseline passive blade. Although a feasible final design was obtained through the procedure described above, it was a time-consuming process with limited applicability. Moreover, the manually-driven iterative process did not guarantee an optimum design at the end. Therefore, it becomes imperative to apply the principle of mathematical optimization into the design task of an active blade.

There have been different studies in the literature that apply the principle of mathematical optimization into the design of rotor blades, examples of which can be found in Refs. [15], [16], and [17]. These studies focused on the design optimization of passive rotor blades, particularly to minimize vibration. When dealing with active blade design, another layer of complexity is added to the problem. An indirect way of addressing vibration control is by maximizing actuator authority. This must happen while a series of other constraints are being satisfied. This paper presents a proposed optimization design framework for active helicopter blades with embedded piezocomposite actuators.

\section{OPTIMIZATION DESIGN FRAMEWORK}

As introduced in the previous section, the proposed framework should seek for the optimum cross-sectional design of an active twist rotor blade with embedded piezocomposite actuators. In mathematical terms, the problem can be stated as:

$$
\max _{x} f(x)
$$

subject to:

$$
\begin{array}{r}
g(x) \leq 0 \\
x_{l} \leq x \leq x_{u}
\end{array}
$$

where $f$ represents the static tip twist induced in the blade by the embedded piezocomposite actuators, $x$ is the set of design variables that are bound between a lower $\left(x_{l}\right)$ and an upper $\left(x_{u}\right)$ limits. Finally, $g(x)$ represents the set of nonlinear constraints.

As illustrated in Fig. 1, the design variables that can be used in the optimization problem are:

1. The thickness and lamination angle of each ply in the cross-section lay-up. The material properties used in each ply, however, must be chosen in advance; 

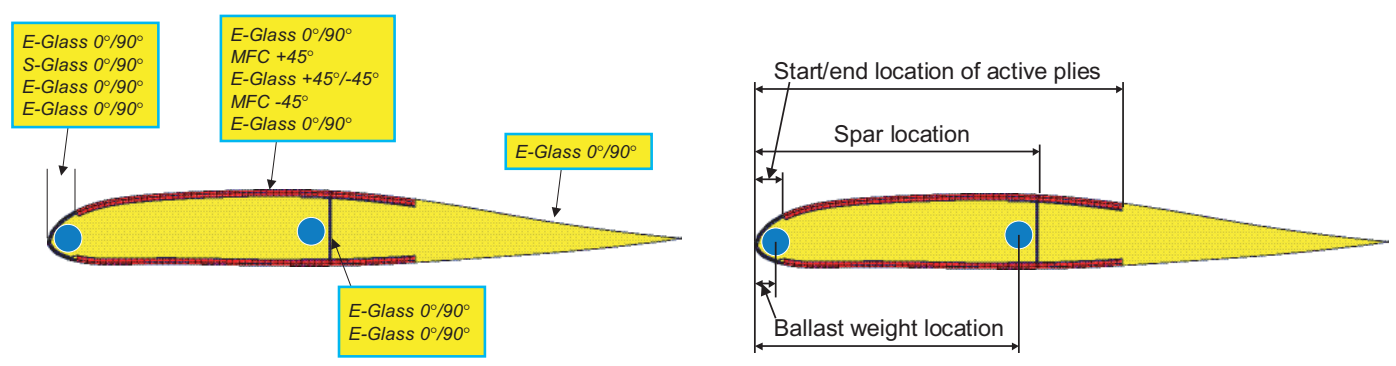

Figure 1: Illustration of (a) initial lay-up configuration for an ATR blade and (b) some of its design variables

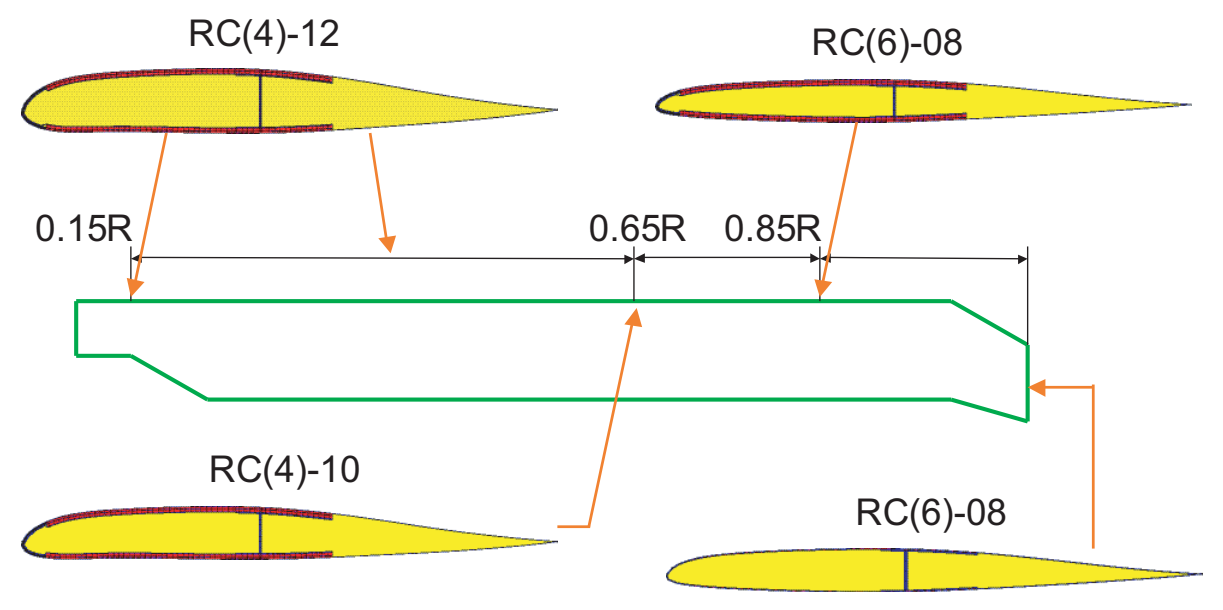

Figure 2: Example of planform and cross section geometry of an advanced ATR blade

2. The starting and ending locations of the active region;

3. The chordwise location of the spar (web) wall;

4. The length of the web extension;

5. Two discrete ballast weights with their masses and chordwise locations.

These variables may be introduced at different blade radius, and they may be linked within a given spanwise region or among different regions of the blade. In the current implementation, the blade planform is subdivided in four regions of predetermined length. Each region may have a different airfoil. The cross section of each of the first three most inboard regions will contain design variables in the proposed framework. The most outboard region represents the blade tip, and its cross-sectional layup may be linked with the one from the neighboring inboard region. The blade planform includes pretwist and tip droop/sweep, so to model modern helicopter blade configurations. An example is shown in Fig. 2. Due to manufacturing constraints, the chordwise location of the spar web should be considered a single design variable along the blade radius. In fact, if more parameters need to be linked from practical manufacturing considerations, it can be done as well. Finally, the permissible range of each design variable type is also imposed based on practical considerationss.

Regarding the constraints $(g(x))$, the following set has been implemented in the proposed framework:

1. Chordwise location of the cross-sectional center of gravity;

2. Chordwise location of the cross-sectional elastic axis;

3. Blade mass per unit span (for correct Lock number); 


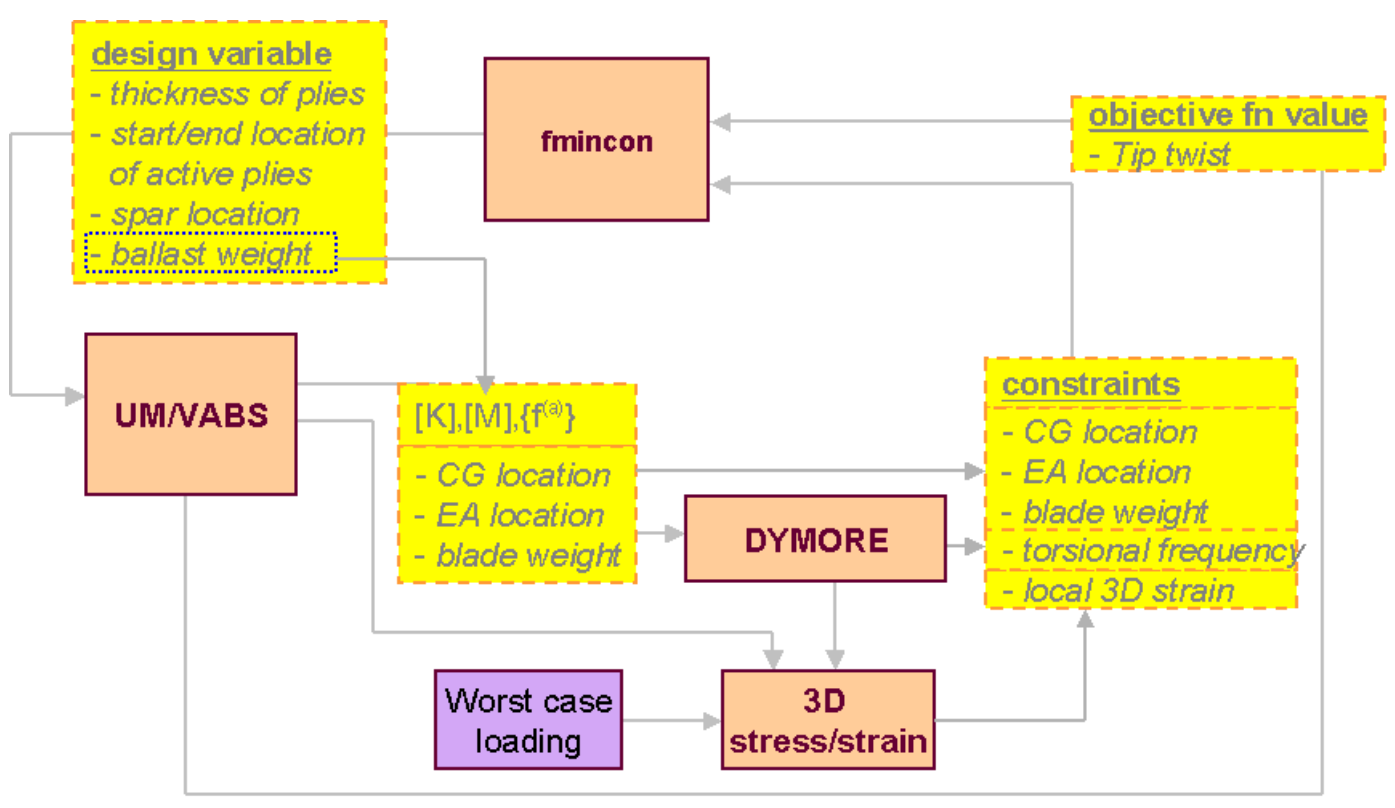

Figure 3: Flow chart of the design optimization framework for active twist rotor blades

4. Blade fundamental rotating frequencies (for desirable blade dynamics);

5. Maximum allowable blade local strain under the worst-case loading condition (associated with the ultimate strength of the constituent materials).

Besides these, some extra constraints were added to better pose the problem (e.g., end of the active region within the cross section must come at a chordwise location greater than the beginning of the same region, etc.).

The implementation of the proposed framework is schematically described in Fig. 3. The environment used to integrate different analysis tools is MATLAB [18]. In the implementation described in this paper, the following numerical tools are used: UM/VABS, cross-sectional parametric mesh generator, DYMORE, 3-D strain module, and MATLAB.

$\mathrm{UM} / \mathrm{VABS}$ is a finite-element based analysis of active cross sections with arbitrary geometry and material distributions [19]. It provides cross-sectional stiffness, inertia and actuation forces/moments parameters to be used in the one-dimensional (beam) modeling of the blade. It also calculates the locations of the center of gravity and elastic axis, the blade mass per unit span, and the static active twist rate (in a given cross section). UM/VABS input has a NASTRAN-based format.

Since UM/VABS is a finite-element application, it is crucial to have an automated mesh generator that can take a few parametric inputs and generate the needed mesh. This is accomplished with a MATLAB-based mesh generator specially developed for UM/VABS [20]. To create a general airfoil wet surface, pairs of coordinate points defining the contour of the airfoil must be supplied. Contour equations have been implemented for the NACA four- and five-digit series airfoils. From the wet surface in, layers of given (composite) material are defined so to create the stacking sequence needed for the internal structural configuration. Materials are defined as both passive and active ones. Through a look-up table, their properties are loaded for each layer. Although UM/VABS can deal with any type of internal cross-sectional geometry, the mesh generator is limited to modeling walls and webs only (no foam or honeycomb filling, for example). The inertial effects associated with the ballast masses are added directly to the inertia matrix generated in UM/VABS.

Another important component part of the design framework is the one-dimensional global blade analysis. The analysis is conducted in DYMORE, a multibody dynamics code developed by Bauchau and co-workers [21]. The exact solution of the geometric nonlinear beam problem provides the blade natural frequencies at normal 

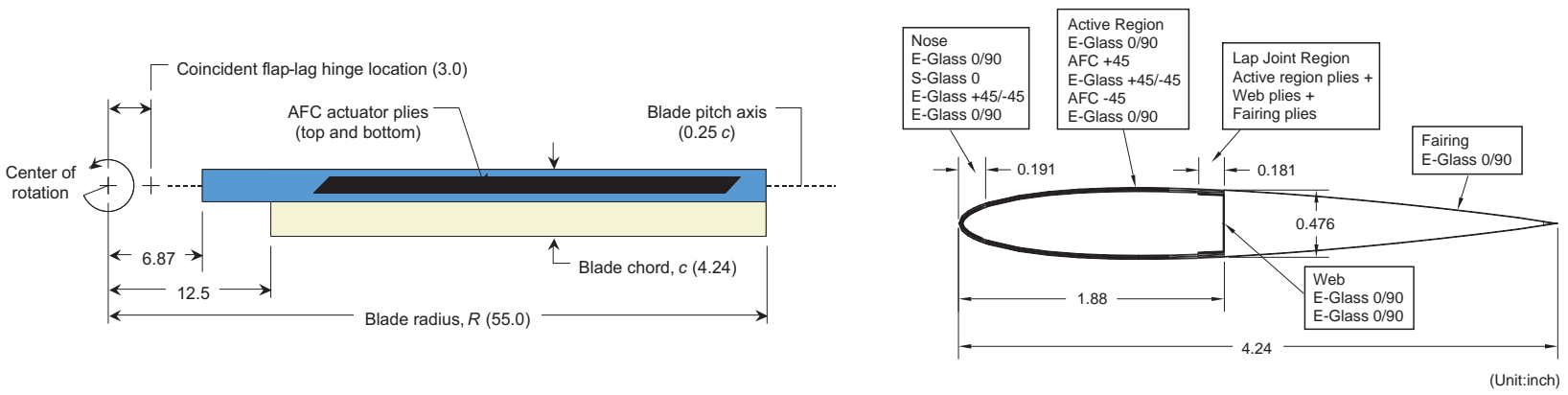

Figure 4: Planform and cross section of the NASA/Army/MIT ATR blade (dimensions are in inches.)

rotating conditions. For the spanwise blade stations that correspond to a constant airfoil section, the crosssectional analysis results obtained from UM/VABS are passed directly into DYMORE. At the short transitional stations between those blade regions, cross-sectional properties are assumed to be linearly-varying with blade radius.

For given blade structural properties and loads, internal local 3-D strain and stress fields can be computed. In the current implementation, worst case sectional blade loads associated with flap bending, chordwise bending, and torsion must be supplied. Centrifugal forces are calculated within DYMORE and added to the set of those given loads. Although this may be at best a conservative estimate, it simplifies tremendously the design process. These loads can be evaluated off line with DYMORE or another aeroelastic code for a baseline blade configuration. They are then used with the information provided by UM/VABS to recover the local strain components at every cross-section point everywhere in the blade. The maximum strain criterion is applied for each of the components of the strain and compared to the allowable of the local constituent material. In the future, the prescribed loads will be replaced by an appropriate aeroelastic calculation for the exact structural properties within a given design cycle.

Finally, gradient-based constrained optimization is performed within MATLAB, using "fmincon" from its optimization toolbox. The "fmincon" function minimizes a constrained nonlinear multivariable problem. The medium scale option is used, which is associated with a sequential quadratic programming method. At each iteration, the function solves a quadratic programming subproblem [22] which improves convergence [23]. The gradients of the objective function and the constraints are provided from finite difference (implemented in the framework). The BFGS (Broyden-Fletcher-Goldfarb-Shanno) method [24], a well known quasi-Newton algorithm for unconstrained optimization, is used in this method. Three kinds of termination criteria have been applied: maximum number of iterations, tolerance on the design variables, and tolerance on the function value. When one of these termination criteria is satisfied, the optimization loop will end. In case the result indicates that the solution still needs more iterations, the optimization can be restarted from the point where it stopped previously.

Since the objective function is highly nonlinear, and since the design hyperspace is very complex, it is possible for "fmincon" to fall into a local extrema, leading to a sub-optimal solution. Therefore, it is necessary to run the optimization to completion, starting from different initial points. When the problem is infeasible, "fmincon" attempts to reduce the distance to the most violated constraint boundary. Thus, it is recommended to start with a feasible initial point if possible.

\section{NUMERICAL EXAMPLE}

In order to exemplify the capabilities of the developed formulation, the NASA/Army/MIT ATR blade is used as a reference case. By selecting different sets of design variables and constraints, alternatives to the original design are generated. 
Table 1: Characteristics of the ATR blade

\begin{tabular}{|c|c|}
\hline Rotor type & $\begin{array}{c}\text { Fully } \\
\text { articulated }\end{array}$ \\
\hline Number of blades, $b$ & 4 \\
\hline Blade chord, $c$ & $10.77 \mathrm{~cm}$ \\
\hline Blade radius, $R$ & $1.397 \mathrm{~m}$ \\
\hline Solidity, $b c / \pi R$ & 0.0982 \\
\hline Airfoil section & NACA 0012 \\
\hline Blade pretwist & $-10^{\circ}$ \\
\hline Hinge offset & $7.62 \mathrm{~cm}$ \\
\hline Root cutout & $31.75 \mathrm{~cm}$ \\
\hline Pitch axis & $25 \%$ chord \\
\hline Elastic axis & $19.6 \%$ chord \\
\hline Center of gravity & $23.2 \%$ chord \\
\hline Lock number & 9.0 \\
\hline Tip Mach number & 0.6 \\
\hline Centrifugal loading at tip & $738.5 \mathrm{~g}$ \\
\hline Rotor speed & $687.5 \mathrm{rpm}$ \\
\hline Rotor overspeed & $756 \mathrm{rpm}$ \\
\hline Mass per unit span $(\mathrm{kg} / \mathrm{m})$ & 0.710 \\
\hline Center of gravity & $17.9 \%$ \\
\hline$E A(\mathrm{~N})$ & $1.78710^{6}$ \\
\hline$G J\left(\mathrm{~N}-\mathrm{m}^{2}\right)$ & $3.14310^{1}$ \\
\hline$E I_{\text {flap }}\left(\mathrm{N}-\mathrm{m}^{2}\right)$ & $4.41910^{1}$ \\
\hline$E I_{\text {lag }}\left(\mathrm{N}-\mathrm{m}^{2}\right)$ & $1.15310^{3}$ \\
\hline Section torsional inertia $\left(\mathrm{kg}-\mathrm{m}^{2} / \mathrm{m}\right)$ & $3.81010^{-4}$ \\
\hline 1st torsion frequency @ 687.5 rpm & $6.97 / \mathrm{rev}$ \\
\hline $\begin{array}{c}\text { Twist actuation @ } 0 \mathrm{rpm} \text {, } \\
2,000 \mathrm{~V}_{\mathrm{pp}} / 0 \mathrm{~V}_{\mathrm{DC}} \\
\text { (amplitude, } \operatorname{deg} / \mathrm{m})\end{array}$ & 1.25 \\
\hline
\end{tabular}

\section{Baseline ATR Blade Characteristics}

As briefly described above, the original requirements for the NASA/Army/MIT ATR blade came from an existing passive blade used by NASA Langley. That blade has been well studied and characterized over the years, and it has the geometry and nondimensional characteristics that are representative of a generic production helicopter blade [25]. The ATR blade was designed to be tested in heavy gas (R134a) medium. Table 1 summarizes its main characteristics. The design employed a total of 24 active fiber composite (AFC) actuators placed on the front D-spar only, and distributed in six stations along the blade span [14]. The ATR final design was determined by manual iterations in search for maximum static twist actuation. Fig. 4 shows ATR blade planform and its cross section. The material properties of the passive prepregs and the AFC plies used in the blade are summarized in the appendix of Ref. [14]. The original ATR design was successfully manufactured and tested and this will serve here as the reference for the optimization exercise.

\section{Blade Optimization Case 1}

For this first case, the constraints are set such that the ATR reference blade design is a feasible solution, as summarized in Table 2. The objective is to determine the internal cross-section configuration such that the characteristics of the numerically optimized blade are the same as the ATR reference blade but with a higher twist actuation authority. Therefore, the problem resumes in maximizing the twist actuation while keeping ply thicknesses and ply angles fixed. The design variables are only the length of the web extension, the spar location, ballast weights and their locations, and the start/end of the active regions. These give a total of 8 design variables, and their initial values are presented in Table 3 (corresponding to the ATR reference blade). 
Table 2: Constraints and bounds for Case 1

\begin{tabular}{||c|l||}
\hline Center of gravity & $0.20 \mathrm{c}<\mathrm{CG}<0.28 \mathrm{c}$ \\
\hline Elastic axis & $0.17 \mathrm{c}<\mathrm{EA}<0.25 \mathrm{c}$ \\
\hline Blade mass/length & $0.656<m<0.72$ \\
\hline 1st torsional frequency & $1 \mathrm{~T}<8.0 / \mathrm{rev}$ \\
\hline Local strain & $\begin{array}{l}\text { max strain }<\text { ultimate } \\
\text { strength of the } \\
\text { constituent material }\end{array}$ \\
case loading & $0.5<t_{k}<5.0$ \\
\hline \hline Ply thickness & $0.05 \mathrm{c}<$ Web $_{e x t}<0.1 \mathrm{c}$ \\
\hline Web extension & $0.0455 \mathrm{c}<\mathrm{Location}<0.85 \mathrm{c}$ \\
\hline Active region & $0.1 \mathrm{c}<\mathrm{Spar}_{l o c}<0.85 \mathrm{c}$ \\
\hline Spar location &
\end{tabular}

Table 3: Initial value of the design variables for Case 1

\begin{tabular}{||c|c||}
\hline All ply thicknesses & 1.0 \\
\hline Active start & $0.0455 \mathrm{c}$ \\
\hline Active end & $0.45 \mathrm{c}$ \\
\hline Web extension & $0.05 \mathrm{c}$ \\
\hline Ballast masses $(\mathrm{kg})$ & $(0.23,0.215)$ \\
\hline Ballast mass locations & $(0.027 \mathrm{c}, 0.432 \mathrm{c})$ \\
\hline Spar location & $0.4438 \mathrm{c}$ \\
\hline
\end{tabular}

Fig. 5(a) shows the convergence history of the normalized (with respect to the ATR reference tip twist actuation) objective function and various normalized blade parameters: locations of the center of gravity and elastic axis, blade mass per unit length, first torsional frequency and the maximum strain. The shaded yellow area represents the feasible range of these parameters. The convergence history of the spar location, length of the web extension, position of the front and rear ballast weights, and start and end of the active region are shown as function of the chordwise position in the airfoil in Fig. 5(b). As it can be seen, in only three iterations the maximum normalized tip twist reached 1.193. This indicates, for this particular case, an increase of approximately $20 \%$ over the ATR reference blade. The start and end chordwise location of the active region are pushed to the bounds. This indicates the desire of adding more active material in the cross section. The spar location was pushed back by approximately $5 \%$ to 0.49 of the chord. The resulting length of the web extension was $5 \%$ chord. The front ballast mass was set aligned with the beginning of the active region, while the rear ballast mass ended up in front of the front web extension, near 0.418 chord. The maximum strain was the active constraint, with the inplane shear strain finishing right up against the allowable of 6800 microstrain. These results are summarized in Table 4.

\section{Blade Optimization Case 2}

Originally, it was desirable for the ATR blade to have both the center of gravity and the elastic axis located at $25 \%$ chord. This requirement comes from blade dynamics and aeroelastic stability considerations. Moreover, the blade first natural torsional frequency should be lower than 5.0/rev at the nominal rotating condition. However, these conditions were not achieved within the original ATR reference blade design. Now, consider seeking for a new design solution that satisfies those constraints shown in Table 5.

Three sub-cases are presented here:

Case 2.a) This case uses the same set of design variables as Case 1, for a total of 8 variables. The difference here is that this case is subjected to the constraints defined in Table 5.

Case 2.b) Same as Case 2.a but with the addition of (9) ply thicknesses to the set of design variables, totaling 17 
Table 4: Reference and optimization results for Case 1

\begin{tabular}{|c|c|c|}
\hline & $\begin{array}{c}\text { ATR } \\
\text { reference } \\
\text { blade }\end{array}$ & $\begin{array}{c}\text { Case 1 } \\
\text { optimized } \\
\text { configuration }\end{array}$ \\
\hline $\begin{array}{l}\text { Active layer } \\
\text { properties }\end{array}$ & $\overline{\mathrm{AFC}}$ & AFC \\
\hline $\begin{array}{l}\text { Tip twist } \\
\text { (deg) }\end{array}$ & 1 & 1.19 \\
\hline $\begin{array}{l}\text { CG location } \\
(\% \mathrm{c})\end{array}$ & 23.20 & 24.00 \\
\hline $\begin{array}{l}\text { EA location } \\
(\% \mathrm{c})\end{array}$ & 19.62 & 19.00 \\
\hline $\begin{array}{c}\text { Blade mass/length } \\
(\mathrm{kg} / \mathrm{m})\end{array}$ & 0.7103 & 0.70 \\
\hline $\begin{array}{c}\text { 1st torsional } \\
\text { frequency }(1 / \mathrm{rev})\end{array}$ & 6.32 & 6.06 \\
\hline $\begin{array}{l}\text { Strain in worst } \\
\text { case loading - } \\
\text { shear } \\
\text { (microstrain) }\end{array}$ & 6327 & $\begin{array}{l}6732 \\
(\text { limit } \\
6800)\end{array}$ \\
\hline
\end{tabular}

design variables. The "ply thickness" used here is actually the multiple of the nominal prepreg ply thickness. Although it should be an integer number, all design variables are treated as continuous ones.

Case 2.c) Same as Case 2.a but now with the addition of (12) ply angles to the set of design variables, totaling 20 design variables.

Table 5: Constraints for Cases 2.a, 2.b, and 2.c

\begin{tabular}{||c|l||}
\hline Center of gravity & $0.22 \mathrm{c}<\mathrm{CG}<0.28 \mathrm{c}$ \\
\hline Elastic axis & $0.22 \mathrm{c}<\mathrm{EA}<0.28 \mathrm{c}$ \\
\hline Blade mass/length & $0.67<m<0.71$ \\
\hline 1st torsional frequency & $1 \mathrm{~T}<5.0 / \mathrm{rev}$ \\
\hline $\begin{array}{c}\text { Local strain } \\
\text { in the worst } \\
\text { case loading }\end{array}$ & $\begin{array}{l}\text { max strain }<\text { ultimate } \\
\text { strength of the } \\
\text { constituent material }\end{array}$ \\
\hline \hline Ply thickness & $0.5<\mathrm{t}_{\mathrm{k}}<5.0$ \\
\hline Web extension & $0.05 \mathrm{c}<$ Web $_{e x t}<0.1 \mathrm{c}$ \\
\hline Active start/end & $0.0455 \mathrm{c}<\mathrm{Location}<0.85 \mathrm{c}$ \\
\hline Spar location & $0.1 \mathrm{c}<$ Spar $_{l o c}<0.85 \mathrm{c}$ \\
\hline
\end{tabular}

Tables 6 and 7 contain the initial values for the design variables. Case 2.c was originally started with the same initial conditions as Cases 2.a and 2.b but it was not able to terminate successfully. Table 7 reflects the changes in the initial condition that resulted in a converged optimum result. With those initial values for the design variables, the optimization framework produced the results summarized in Table 8. From these results, the first thing to observe is that even though the constraints are tighter in these cases than they are in Case 1, a solution with better performance than the original ATR reference blade can still be obtained. In fact, Case 2.a shows that the new constraints can be accommodated by the same set of design variables as in Case 1 and provides very similar twist actuation performance. Among the three cases, Case 2.b presents the highest twist actuation. However, since ply thicknesses are integer quantities (multiple of the nominal ply thickness), 


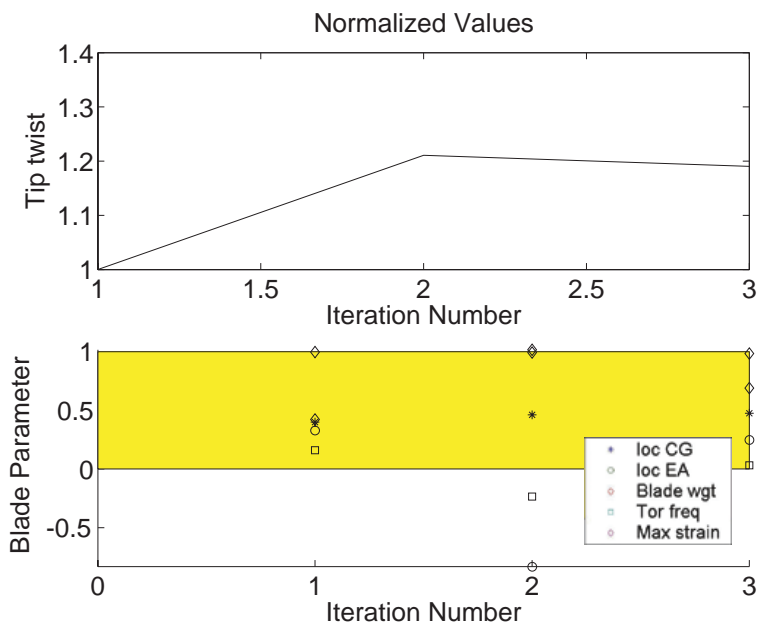

(a)

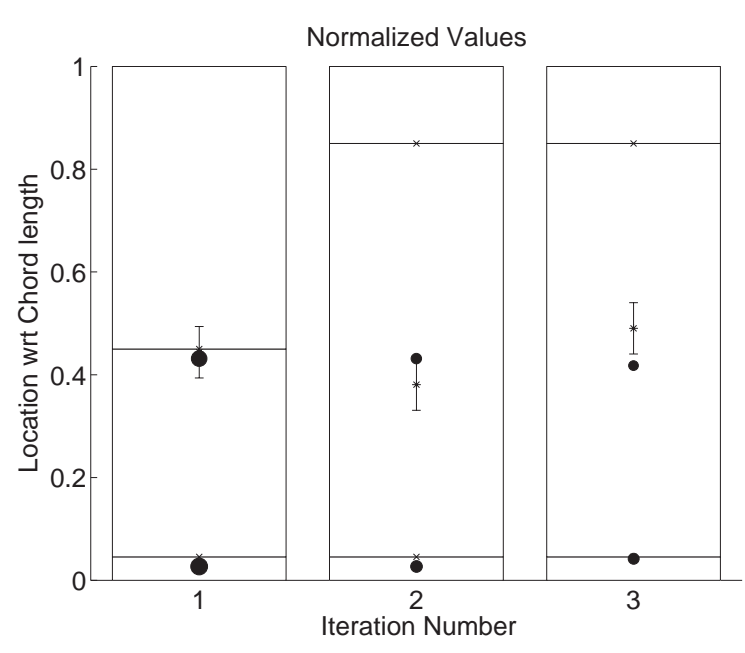

(b)

Figure 5: Case 1 results: (a) objective function convergence history (top) and normalized blade parameters (bottom), and (b) spar location $(*)$, web extension $(\mid)$, front and rear ballast weights $(\bullet)$, and start and end of active region $(-x-)$, all normalized by chord length

this optimum solution is not quite practical. Allowing an adjustment on the ply angles provided an extra $10 \%$ increase in the twist authority from Case 2.a.

Table 6: Initial design values for Cases 2.a and 2.b

\begin{tabular}{||c|c||}
\hline All ply thickness & 1.0 \\
\hline Active start & $0.0456 \mathrm{c}$ \\
\hline Active end & $0.85 \mathrm{c}$ \\
\hline Web extension & $0.05 \mathrm{c}$ \\
\hline Ballast weight mass & $(0.186,0.105)$ \\
\hline Ballast weight location & $(0.022 \mathrm{c}, 0.85 \mathrm{c})$ \\
\hline Spar location & $0.634 \mathrm{c}$ \\
\hline
\end{tabular}

Figs. 6(a), 7(a), and 8(a) show the convergence history of the normalized objective function and various normalized blade parameters for Cases 2.a, 2.b, and 2.c, respectively. Again, the shaded yellow area represents the feasible range of these parameters. The convergence history of the spar location, length of the web extension, position of the front and rear ballast weights, and start and end of the active region are shown as function of the chordwise position in the airfoil in Figs. 6(b), 7(b), and 8(b).

From Fig. 6(a) one can see that Case 2.a converged already on the second iteration. The feasible initial values for the design variables were such that the optimizer could not find a better solution. The web was located at 0.635 chord, a further aft position than the previous cases. The active region extended over most of the airfoil, starting at $4.5 \%$ chord and ending at $85 \%$ chord. Case 2.b took approximately 25 iterations to converge. The location of the elastic axis was difficult to keep within the required bounds. Fig. 9(a) shows the evolution of the ply thicknesses with number of iterations. Results were between 0.5 and 1.85 of a nominal ply thickness. Since 0.5 is a lower bound for the thickness design variable, this indicates that the optimizer is trying to eliminate some of the plies in favor of others. Unfortunately, complete elimination of plies by zeroing their thickness parameter cannot be currently handled by the automated mesh generator. The web location resulted at $74 \%$ chord, and the active region extends to its limits.

Case 2.c, with varying ply angles, took the longest to converge among these three cases with the given initial conditions. As it can be seen in Fig. 8(a), it took approximately 60 iterations for the optimizer to produce the 


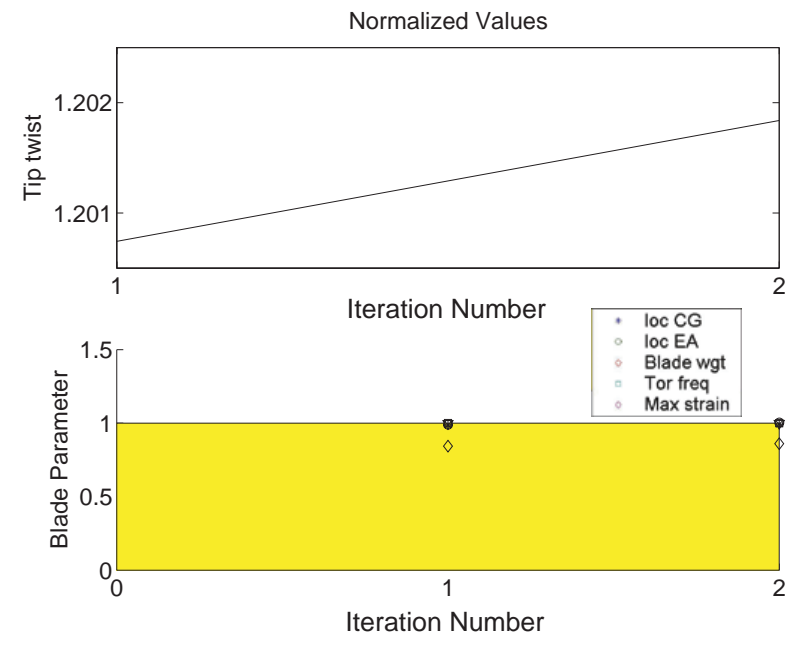

(a)

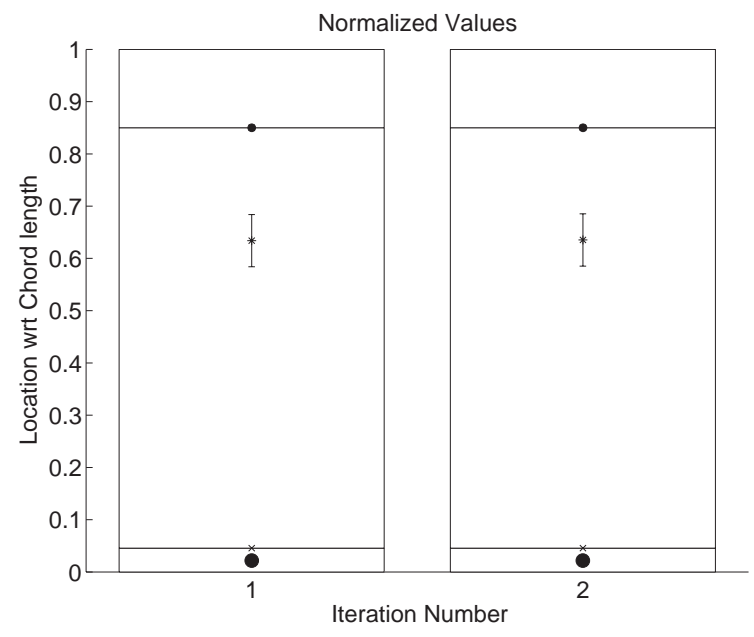

(b)

Figure 6: Case 2.a results: (a) objective function convergence history (top) and normalized blade parameters (bottom), and (b) spar location $(*)$, web extension $(\mid)$, front and rear ballast weights $(\bullet)$, and start and end of active region $(-x-)$, all normalized by chord length

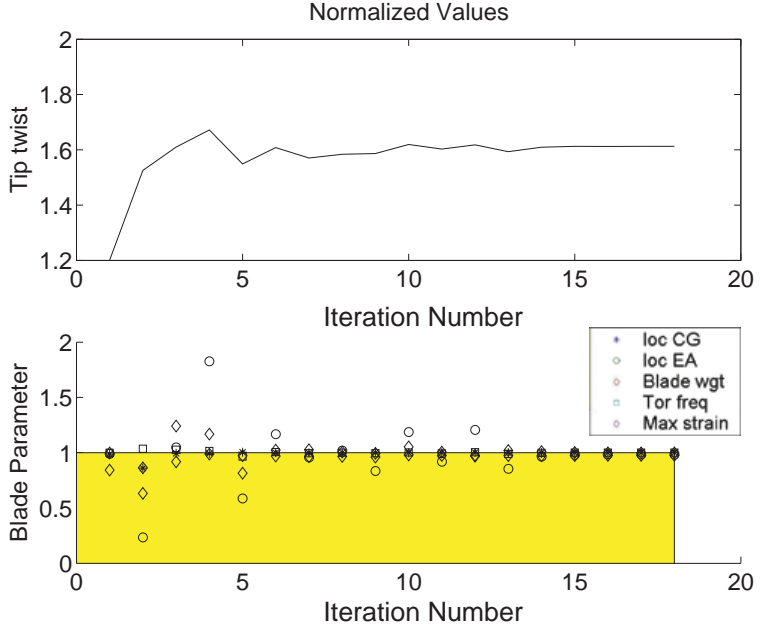

(a)

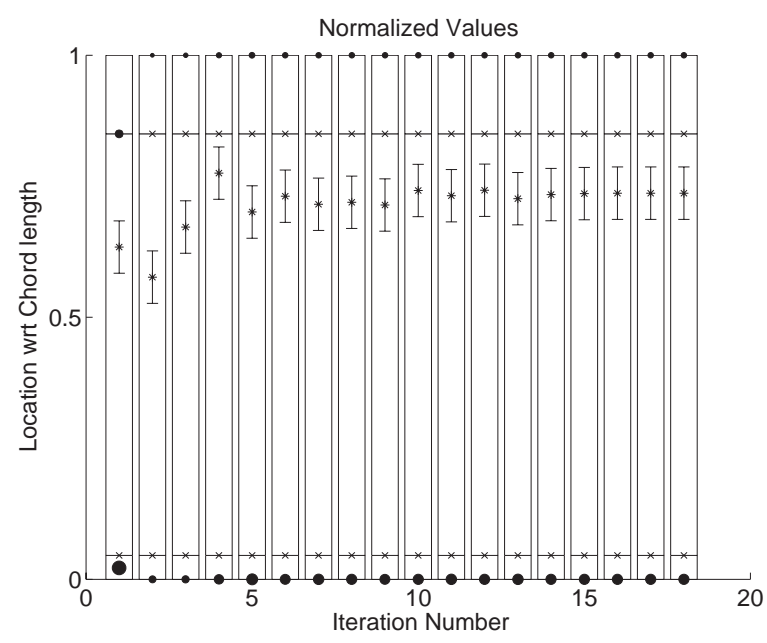

(b)

Figure 7: Case 2.b results: (a) objective function convergence history (top) and normalized blade parameters (bottom), and (b) spar location $(*)$, web extension $(\mid)$, front and rear ballast weights $(\bullet)$, and start and end of active region $(-x-)$, all normalized by chord length 
Table 7: Initial design values for Case 2.c

\begin{tabular}{||c|c||}
\hline All ply thickness & 1.0 \\
\hline Active start & $0.0455 \mathrm{c}$ \\
\hline Active end & $0.85 \mathrm{c}$ \\
\hline Web extension & $0.05 \mathrm{c}$ \\
\hline Ballast weight mass & $(0.195,0.102)$ \\
\hline Ballast weight location & $(0.0 \mathrm{c}, 0.932 \mathrm{c})$ \\
\hline Spar location & $0.790 \mathrm{c}$ \\
\hline
\end{tabular}

Table 8: Baseline and optimization result for Cases 2.a, 2.b, and 2.c

\begin{tabular}{||c|c|c|c||}
\hline & $\begin{array}{c}\text { Case 2.a } \\
\text { optimized } \\
\text { configuration }\end{array}$ & $\begin{array}{c}\text { Case 2.b } \\
\text { optimized } \\
\text { configuration }\end{array}$ & $\begin{array}{c}\text { Case 2.c } \\
\text { optimized } \\
\text { configuration }\end{array}$ \\
\hline $\begin{array}{c}\text { Active layer } \\
\text { properties }\end{array}$ & AFC & AFC & AFC \\
\hline $\begin{array}{c}\text { Tip twist } \\
\text { (deg) }\end{array}$ & 1.20 & 1.61 & 1.29 \\
\hline $\begin{array}{c}\text { CG location } \\
\text { (\%c) }\end{array}$ & 24.00 & 28.00 & 25.00 \\
\hline $\begin{array}{c}\text { EA location } \\
\text { \%c) }\end{array}$ & 28.00 & 28.00 & 28.00 \\
\hline $\begin{array}{c}\text { Blade mass/length } \\
(\text { kg/m) }\end{array}$ & 0.70 & 0.71 & 0.67 \\
\hline $\begin{array}{c}1 \text { st torsional } \\
\text { frequency (1/rev) }\end{array}$ & 5.00 & 5.00 & 6603 \\
\hline $\begin{array}{c}\text { Strain in worst } \\
\text { case loading - } \\
\text { shear } \\
\text { (microstrain) }\end{array}$ & 6787 & 6628 & $6800)$ \\
\hline
\end{tabular}

optimum result presented herein. The severe discontinuity after iteration number 30 is due to the fact that the process stopped after reaching the preset maximum number of iterations. Some of the initial values of the design variables were adjusted to produce a feasible solution and the process restarted. Notice that the location of the elastic axis and the strength constraints were the most difficult ones to satisfy. The final design does not present an active twist authority as high as the one from Case 2.b, but it is higher than Case 2.a. This indicates for this case that the addition of the ply angles as design variables improves the objective function by another $10 \%$. The active region is again covering most of the airfoil. The web location is now at $60 \%$ chord, and the two ballast weights are at the nose and very near the trailing edge (92\% chord location). Unfortunately, this last result is not physically feasible since the trailing edge does not offer an appropriate attachment point that can take the concentrated inertia loads generated by the presence of the ballast mass. This will be addressed in future work.

\section{GENERAL OBSERVATIONS}

While running the optimization cases discussed previously, some practical observations were made. Among them:

1. Due to the fact that the optimizer may work in the infeasible domain, extra constraints were added in order to keep the mesh generator from crashing. A different optimization algorithm that does not violate constraints and bounds may be a better choice for this problem. This may demand an interior method (feasible region only). 


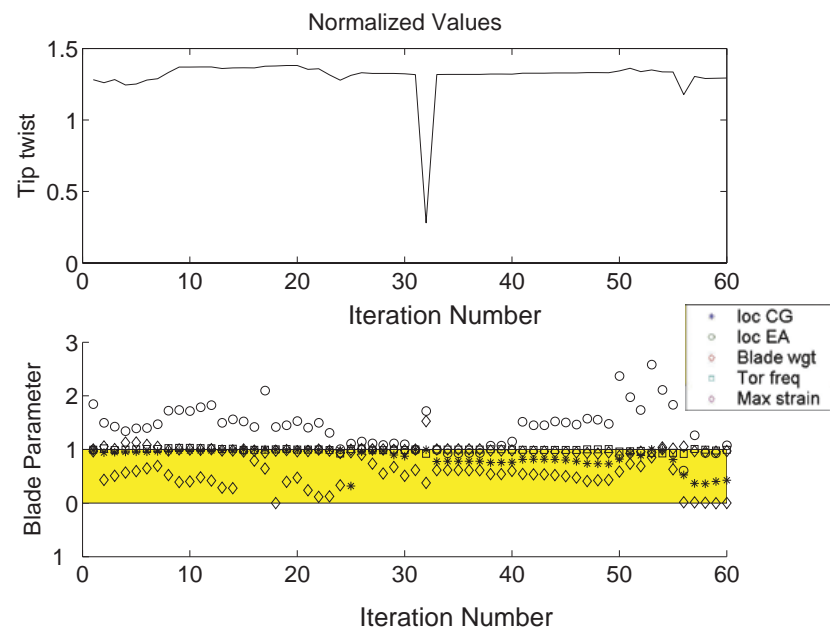

(a)

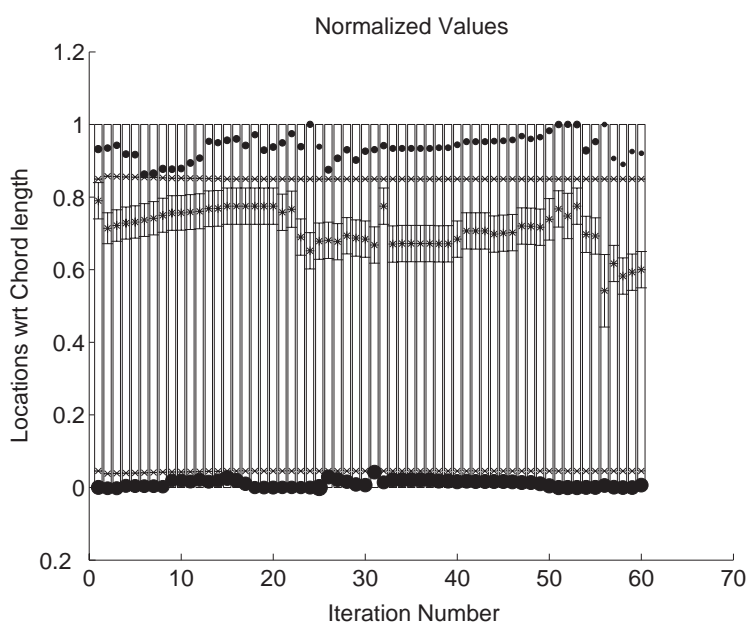

(b)

Figure 8: Case 2.c results: (a) objective function convergence history (top) and normalized blade parameters (bottom), and (b) spar location $(*)$, web extension $(\mid)$, front and rear ballast weights $(\bullet)$, and start and end of active region $(-x-)$, all normalized by chord length

2. It is very helpful to have three constraints associated with maximum strain (two normal and one inplane shear components) instead of just the single most critical component. This avoids discontinuity in the constraint, reducing its nonlinear characteristics. Also, by considering three components, the resulting strain/stress may be better distributed in the cross section.

3. Including ply angles among the design variables made it significantly more difficult for the optimizer to converge.

4. The mesh generator ended up not being as problematic as it was originally expected. There are only few critical condition that induces it to crash. In theory one can avoid those conditions by setting bounds and constraints. In practice, since it is not possible to force the current optimizer to obey the set bounds, special attention still needs to be given to the mesh generation for the cross-sectional analysis.

5. For the examples run, the maximum strain seemed to occur at the same place (or similar) every time: right at the point of discontinuity in ply thickness between the active region and the nose region in the cross section.

6. Adding a passive ply in the nose seemed to reduce the stress concentration which arose from the discontinuity in ply thickness to the left of the active region (toward the leading edge). Although more investigation is needed, it seems that by adding an additional S-glass ply in the nose region to smooth the discontinuity will reduce the maximum strain for the same load.

7. In the case of wind tunnel model design, a web may not be needed to satisfy the requirements imposed in this design problem. This can be seem from some of the optimization cases when the optimizer pushes the web location as far back as possible. To address that, one may want to introduce the existence of the spar as a design variable.

8. The ability to eliminate an undesirable ply through reducing its thickness to zero should be implemented. For that, modifications must be made on the automated mesh generator.

9. Fixing the ballast masses to be just behind the leading edge and just behind the spar caused problems with the mesh generation. Further investigation is required to devise a fix to this limitation.

10. Implementing a mixed continous/discrete optimization algorithm could be useful, especially for layer thicknesses and ply angles. Some preliminary work has started to investigate its feasibility for this problem. 


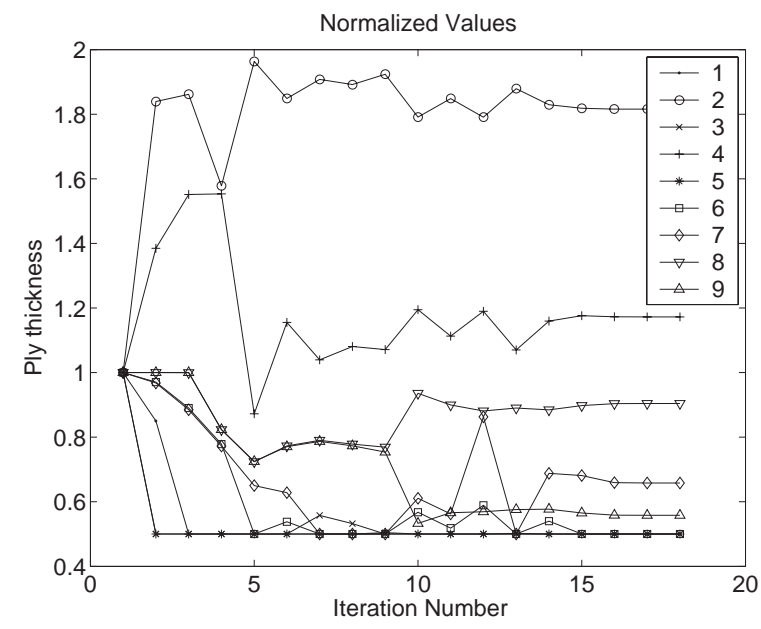

(a)

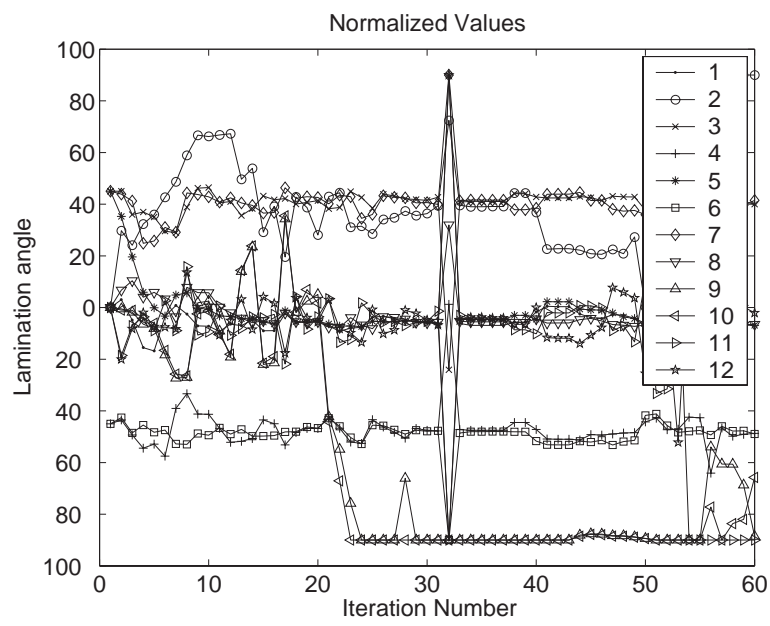

(b)

Figure 9: Evolution of (a) ply thicknesses for Case 2.b and (b) ply angles for Case 2.c

11. The nonlinear nature of the problem under consideration and the chosen gradient-based optimization scheme, as expected, make the solution sensitive to the initial values of the design variables (local optimum). The optimizer converged much faster to a local optimum when the initial point was a feasible one.

\section{CONCLUDING REMARKS}

This paper presented the initial development of an optimization framework for active helicopter rotor blade cross-sectional design. It allows for the exploration of the rich and highly nonlinear design space facing the sizing of active twist rotor blades. Different analytical components are combined in the framework: cross-sectional analysis, automated mesh generator, one-dimensional beam solver, 3-D local strain module, and numerical optimization routine. Through the mathematical optimization problem, static twist actuation performance of a blade is maximized while satisfying certain blade constraints. The developed framework is exemplified in the NASA/Army/MIT ATR blade case. The examples showed that the original ATR blade, successfully manufactured and tested, could exhibit at least $20 \%$ higher actuation performance if designed within the optimization framework presented in this paper.

\section{ACKNOWLEDGMENTS}

This work has been supported by NASA Langley Research Center under cooperative agreement NCC1-323. The technical monitor is Mr. Matthew L. Wilbur.

\section{REFERENCES}

[1] Shaw, J., N., Albion, J., Hanker E., and Teal, R. S., "Higher Harmonic Control: Wind Tunnel Demonstration of Fully Effective Vibratory Hub Force Suppression," Journal of the American Helicopter Society, Vol. 31, No. 1, 1989, pp. 14-25.

[2] Ham, N. D., "Helicopter Individual-Blade-Control Research at MIT 1977-1985," Vertica, Vol. 11, No. 1/2, 1987, pp. 109-122.

[3] Nguyen, K., Betzina, M., and Kitaplioglu, C., "Full-Scale Demonstration of Higher Harmonic Control for Noise and Vibration Reduction on the XV-15 Rotor," In Proceedings of the American Helicopter Society 56th Annual Forum, Virginia Beach, VA, May 2-4 2000. 
[4] Loewy, R. G., "Recent Developments in Smart Structures with Aeronautical Applications," In Proceedings of the 37th Israel Annual Conference on Aerospace Sciences, February 26-27 1997.

[5] Friedmann, P. P., "The Promise of Adaptive Materials for Alleviating Aeroelastic Problems and Some Concerns," In Proceedings of Innovation in Rotorcraft Technology, London, United Kingdom, June 24-25 1997, Royal Aeronautical Society, pp. 10.1-10.16.

[6] Chopra, I., "Status of Application of Smart Structures Technology to Rotorcraft Systems," Journal of the American Helicopter Society, Vol. 45, No. 4, 2000, pp. 228-252.

[7] Giurgiutiu, V., "Recent Advances in Smart-Material Rotor Control Actuation," In Proceedings of the AIAA/ASME/ASCE/AHS/ASC 41st Structures, Structural Dynamics and Materials Conference-Adaptive Structures Forum, Atlanta, Georgia, April 3-6 2000, AIAA Paper No. 2000-1709.

[8] Cesnik, C. E. S. and Shin, S.-J., "On the Modeling of Integrally Actuated Helicopter Blades," International Journal of Solids and Structures, Vol. 38, No. 10-13, 2001, pp. 1765-1789.

[9] Wilbur, M. L., Yeager, Jr. W. T., Wilkie, W. K., Cesnik, C. E. S., and Shin, S.-J., "Hover Testing of the NASA/ARMY/MIT Active Twist Rotor Prototype Blade," In Proceedings of the American Helicopter Society 56th Annual Forum, Virginia Beach, VA, May 2-4 2000.

[10] Cesnik, C. E. S., Shin, S.-J., and Wilbur, M. L., "Dynamic Response of Active Twist Rotor Blades," Smart Materials and Structures-Special Issue on Rotorcraft Applications, Vol. 10, 2001, pp. 62-76.

[11] Wilbur, M. L., Mirick, P. H., Yeager, Jr. W. T., Langston, C. W., Cesnik, C. E. S., and Shin, S.-J., "Vibratory Loads Reduction Testing of the NASA/ARMY/MIT Active Twist Rotor," Journal of the American Helicopter Society, Vol. 47, No. 2, 2002, pp. 123-133.

[12] Wilbur, M. L., Yeager, Jr. W. T., and Sekula, M. K., "Further Examination of the Vibratory Loads Reduction Results from the NASA/ARMY/MIT Active Twist Rotor Test," In Proceedings of the American Helicopter Society 58th Annual Forum, Montreal, Canada, June 11-13 2002.

[13] Shin, S.-J., Cesnik, C. E. S., and Hall, S. R., "Closed-loop Control Test of the NASA/ARMY/MIT Active Twist Rotor for Vibration Reduction," In Proceedings of the American Helicopter Society 59th Annual Forum, Phoenix, Arizona, May 6-8 2003.

[14] Cesnik, C. E. S., Shin, S.-J., Wilkie, W. K., Wilbur, M. L., and Mirick, P. H., "Modeling, Design, and Testing of the NASA/ARMY/MIT Active Twist Rotor Prototype Blade," In Proceedings of the American Helicopter Society 55th Annual Forum, Montreal, Canada, May 25-27 1999.

[15] Friedmann, P. P., "Helicopter Vibration Reduction Using Structural Optimization with Aeroelastic/Multidisciplinary Constraints - A Survey," Journal of Aircraft, Vol. 28, No. 1, 1991, pp. 8-21.

[16] Walsh, J. L., Young, K. C., Tarzanin, F. J., Hirsh, J. E., and Young, D. K., "Optimization Issues with Complex Rotorcraft Comprehensive Analysis," In Proceedings of the AIAA/USAF/NASA/ISSMO 7th Symposium on Multidisciplinary Analysis and Optimization, St. Louis, MO, September 2-4 1998, AIAA Paper No. 98-4889.

[17] Celi, R., "Recent Applications of Design Optimization to Rotorcraft," Journal of Aircraft, Vol. 36, No. 1, 1999, pp. 176-189.

[18] Coleman, T., Branch, M. A., and Grace, A., Optimization Toolbox For Use with MATLAB, The MathWorks, Inc., Natick, MA, 1999.

[19] Cesnik, C. E. S. and Palacios, R., "Modeling Piezocomposite Actuators Embedded in Slender Structures," In Proceedings of the AIAA/ASME/ASCE/AHS/ASC 44th Structures, Structural Dynamics and Materials Conference- Adaptive Structures Forum, Norfolk, VA, April 7-10 2003, AIAA Paper No. 2003-1803. 
[20] Brown, E. L., "Integrated Strain Actuation In Aircraft With Highly Flexible Composite Wings," Ph.D. Thesis, Massachusetts Institute of Technology, June 2003.

[21] Bauchau, O. A., "Computational Schemes for Flexible, Nonlinear Multi-Body Systems," Multibody System Dynamics, Vol. 2, 1998, pp. 169-225.

[22] www.mathworks.com The MathWorks, Inc., Natick, MA, 2004.

[23] Hafka, R. T. and Gurdal, Z., Elements of structural Optimization, Kluwer Academic Publishers, 1992.

[24] Fletcher, R. and Powell, M. J. D., A Rapidly Convergent Descent Method for Minimization, Computer Journal, Vol. 6, pp. 163-168, 1963.

[25] Wilkie, W. K., Wilbur, M. L., Mirick, P. H., Cesnik, C. E. S., and Shin, S.-J., "Aeroelastic Analysis of the NASA/ARMY/MIT Active Twist Rotor," In Proceedings of the American Helicopter Society 55th Annual Forum, Montreal, Canada, May 25-27 1999. 